\title{
Formula-Based Estimates of the GFR: Equations Variable and Uncertain
}

\author{
Pierre Delanaye $^{\mathrm{a}}$ Eric P. Cohen ${ }^{\mathrm{b}}$ \\ a Department of Nephrology-Dialysis, University of Liège, CHU Sart Tilman, Liège, Belgium; \\ ${ }^{b}$ Department of Medicine, Medical College of Wisconsin, Froedtert Hospital, Milwaukee, Wisc., USA
}

\section{Key Words}

Glomerular filtration rate $\cdot$ Creatinine $\cdot$ MDRD

\begin{abstract}
Regarding the prevalence of chronic kidney disease in the population, estimation of glomerular filtration rate is of importance. Creatinine-based formulas are thus useful as the first step of a prevention strategy. Several creatinine-based formulas have been published. Among these, the CockcroftGault formula and the Modification of Diet in Renal Disease (MDRD) study equation are the most used by physicians. The latter may be automatically reported by laboratories and has thus great success. However, these formulas have limitations. First, the MDRD formulas are not applicable to all populations, notably the healthy one and the patients with abnormal weight (anorectic or obese). Second, we evoke the limitations in the precision of the formulas linked to analytical aspects. Indeed, these analytical limitations remain significant even if they are improved by creatinine standardization. Lastly, we briefly mention the potential impact of these limitations on the epidemiology and the staging of chronic kidney disease.

Copyright $\odot 2008$ S. Karger AG, Basel
\end{abstract}

\section{Introduction}

Identification and treatment of chronic kidney disease (CKD) is a major concern $[1,2]$. Early diagnosis of progressive kidney disease is of the highest importance. Most doctors know the limitations of serum creatinine for the detection of early CKD [3]. Serum creatinine concentration varies with the kidney function, and is also influenced by 'non-nephrological' factors such as sex, race, age and muscular mass. Due to these limitations, one can estimate glomerular filtration rate (GFR) with creatininebased formulas that account for anthropometrical and biological variation [1]. The two best known equations are the equation published in this journal by Cockcroft and Gault in 1976 [4] and the most recent equation published by Levey et al. [5] in 1999 using the data from the Modification of Diet in Renal Disease (MDRD) study (table 1). Table 2 compares the methodology and the population of both studies. The MDRD study estimates GFR in comparison to its measurement by the iothalamate method whereas the Cockcroft equation estimates creatinine clearance, which is not identical to the GFR, sensu stricto [1]. The Cockcroft-Gault population was nearly all male. Another fundamental difference between these two formulas is the mean GFR of the population from which they have been built. These are, respectively, 39.8 
Table 1. MDRD study equations and Cockcroft equation commonly used for GFR estimation

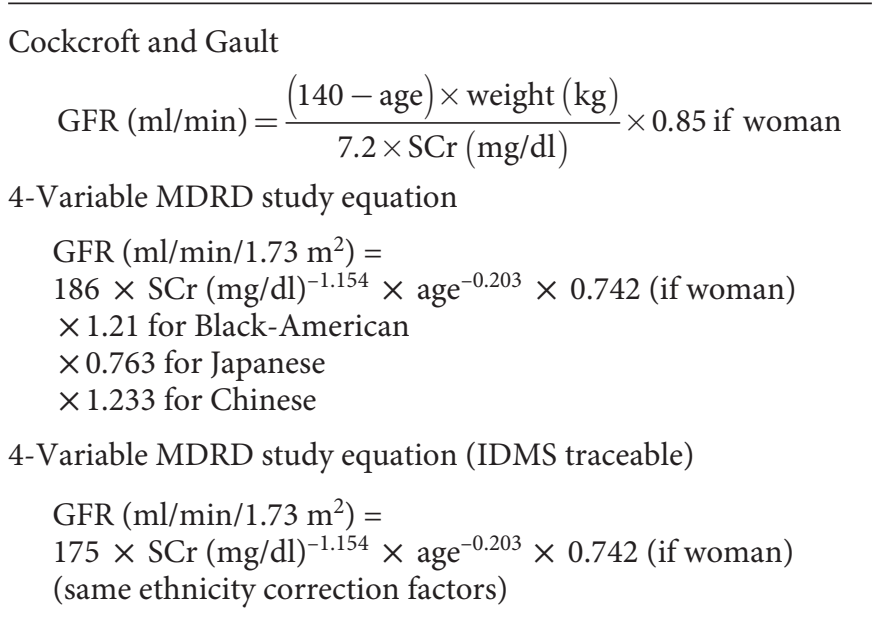

Table 2. Comparison of methodology between the MDRD and the Cockcroft study

\begin{tabular}{|c|c|c|}
\hline & Cockcroft & MDRD \\
\hline Population and reference & Canada 1976 [4] & USA 1999 [5] \\
\hline Sample & 249 & 1,628 \\
\hline Mean GFR & $73 \mathrm{ml} / \mathrm{min}$ & $\begin{array}{l}40 \mathrm{ml} / \mathrm{min} / \\
1.73 \mathrm{~m}^{2}\end{array}$ \\
\hline Reference method & Creatinine clearance & Iothalamate \\
\hline$\%$ women & 4 & 40 \\
\hline$\%$ black & unknown & 12 \\
\hline Mean weight & 72 & 79.6 \\
\hline BSA indexation & no & yes \\
\hline
\end{tabular}

$\mathrm{ml} / \mathrm{min} / 1.73 \mathrm{~m}^{2}$ in the MDRD study versus $72.8 \mathrm{ml} / \mathrm{min}$ in the Cockcroft-Gault cohort.

The MDRD estimated GFR (eGFR) can be reported by clinical laboratories because it requires only knowledge of a person's serum creatinine, age, and sex, the race being interpreted by the clinician. Different correction factors are applied to the MDRD results according to the ethnicity of the patient (summarized in table 1). These factors could increase the accuracy of the MDRD study formulae, contrary to the Cockcroft equation for which no ethnic corrections have been described [6-8]. It is thus not surprising that this equation is used more and more. The simplicity of the Cockcroft equation is thus surpassed. However, the success story of the MDRD study equation does not make it invincible.

Limitations of the Creatinine-Based Equations

\section{MDRD Study Equation}

\section{Good for Everybody?}

As mentioned, the MDRD study equation was built from a CKD population [5]. It is well-known that the relationship between GFR and creatinine is not the same in CKD and healthy subjects [3]. Indeed, the MDRD formula may underestimate the true GFR in healthy subjects. There is substantial imprecision for the result of the eGFR compared to its measured value, when the measured value is $\geq 60 \mathrm{ml} / \mathrm{min} / 1.73 \mathrm{~m}^{2}[9,10]$.

To these mis-estimates two obvious situations can be added in which formula-based estimates of the GFR are futile, even if still commonly reported on laboratory result reports. These are in the patients with acute kidney injury and changing kidney function, and in the patients on chronic dialysis. Those with acute kidney injury are not in the steady state, and those on chronic dialysis have no GFR of their own.

\section{Where Is the Body Weight?}

The Cockcroft-Gault equation uses the weight as a variable [4]. This is logical because the serum creatinine concentration varies with muscular mass. But weight is only an indirect estimation of the muscular mass. Inaccuracies in the equation thus occur when it is applied to obese or cachectic subjects. Several authors have shown the inaccuracy of the Cockcroft formula in these two populations $[11,12]$. The Cockcroft formula could also be misleading when eGFR is longitudinally followed in an obese patient on a weight-loss diet. If the patient loses fat weight, the eGFR by Cockcroft will decrease, probably without a large decrease of true GFR. One may wonder why the weight variable does not appear in the MDRD study equation. This is explained by the fact that the MDRD equation indexes its GFR determination by the body surface area (BSA), and BSA takes into account the body height and weight. However, indexing GFR for BSA is questionable as we have already shown [13]. Indeed, indexing GFR for BSA implies that the relationship between GFR and BSA is linear and that this relationship disappears when indexed GFR is used. This is not true. Indexing GFR will have only minimal impact on the absolute results in the population with normal BMI. The impact of indexing will be high in obese patients [13]. The mean weight of the original MDRD population was 79.6 $\pm 16.8 \mathrm{~kg}$. Most of the patients in the MDRD study were neither severely obese nor cachectic. Independently of the limitations linked to the BSA, Verhave et al. [12] have shown that the MDRD study equation underestimates 


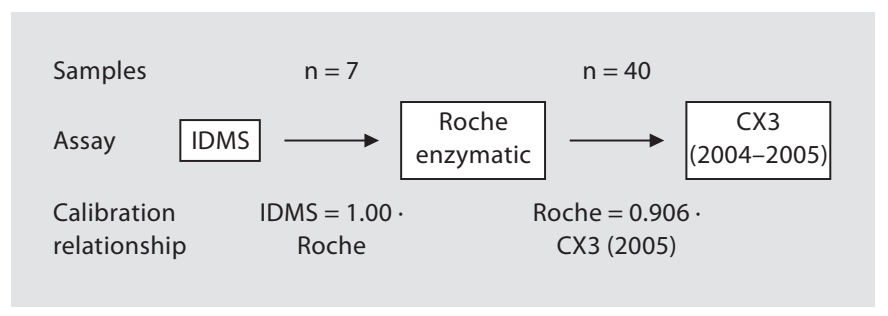

Fig. 1. Steps and results of calibration of the MDRD study samples to creatinine reference materials [reproduced with permission from 18].

measured GFR in obese patients by about $10 \mathrm{ml} / \mathrm{min}$. The main limitation of this study is linked to the fact that most of the subjects had normal GFR and/or creatinine values [14]. We maintain that the use of formula-based estimates of the GFR is imprecise in obese and in underweight subjects, so that formulas are not suitable to search for CKD in these subjects, despite their possible predisposition to kidney disease.

\section{Analytical Limitation}

Due to the exponential relation of the serum creatinine to the GFR, a small change in low creatinine values will have great impact on the GFR. For example, if a patient's creatinine increases from 0.6 to $1.2 \mathrm{mg} / \mathrm{dl}$, this means that he has lost half of his initial GFR. However, if the creatinine rises from 3 to $3.6 \mathrm{mg} / \mathrm{dl}$ in a patient with the same anthropometrical data, the loss of GFR is considerably smaller. Thus, close-to-normal and normal serum creatinine values require attention.

\section{Calibration}

In 2002, Coresh et al. [15] illustrated the impact of differences in creatinine calibration on the GFR estimation. In the NHANES study, the serum creatinine was measured with the kinetic Jaffé method by the Roche assay on the Hitachi 737 machine, whereas in the MDRD study, the serum creatinine was measured with the Beckman method on the CX3 machine. Results of the serum creatinine measurement were systematically $0.23 \mathrm{mg} / \mathrm{dl}$ higher with the Hitachi method. For a 60 -year-old white man with a Beckman serum creatinine of $1 \mathrm{mg} / \mathrm{dl}$, the eGFR is $110 \mathrm{ml} / \mathrm{min} / 1.73 \mathrm{~m}^{2}$. The serum creatinine of the same patient will be $1.23 \mathrm{mg} / \mathrm{dl}$ on the Hitachi apparatus, which by the MDRD formula will give an eGFR of $81 \mathrm{ml} /$ $\mathrm{min} / 1.73 \mathrm{~m}^{2}$. Further, and due to the exponential relation between GFR and creatinine, the impact of the differences of calibration will be greater for lower serum creatinine concentrations. The same difference in calibration will induce a difference of only $6 \mathrm{ml} / \mathrm{min} / 1.73 \mathrm{~m}^{2}$ in the eGFR for the same patient if his serum creatinine was $2 \mathrm{mg} / \mathrm{dl}$. Others have confirmed the potential impact on the eGFR of the differences in creatinine calibration [16].

\section{IDMS-Traceable Creatinine}

The only way to overcome the potential bias linked to the calibration of creatinine is to calibrate the creatinine measurement against an absolute standard [17]. This standard does exist, and it is the measurement of creatinine by isotope dilution mass spectrometry (IDMS). Roche was the first to recalibrate the Jaffé and enzymatic methods to IDMS. Global calibration by other manufacturers is ongoing. Levey et al. [18, 19] have modified the MDRD formula based on these calibrations. In fact, for serum creatinine values traceable to the IDMS result, the factor 186 becomes 175 . Nevertheless, the way this calibration has been obtained is not free from criticism. First, the authors have modified their equation after having recalibrated their Jaffé creatinine (Beckman CX3) to an enzymatic method (Roche Diagnostic) which has been calibrated with the IDMS reference method (fig. 1) [18]. Through their calibrations, the authors have deleted the different intercepts because they were not statistically significant. This is questionable. In fact, even if the intercept between Roche enzymatic and IDMS is not significant and even if the intercept between Roche enzymatic and Beckman CX3 is not significant, this does not necessarily imply that the intercept is not different for the regression of the IDMS versus the Beckman creatinine data! Indeed, Vickery et al. [20] have also measured the direct relation between creatinine measured by IDMS and Beckman CX3. These authors found a slope of 0.99 and an intercept of $-0.18 \mathrm{mg} / \mathrm{dl}$ which is not negligible.

The second criticism regarding the IDMS calibration concerns the calibration curve between the Beckman CX3 creatinine and the Roche enzymatic creatinine (fig. 2). The calibration curve has been obtained on 40 reference sera with creatinine values between 0.5 and $5 \mathrm{mg} / \mathrm{dl}$. From our point of view, the range of creatinine used for the calibration appears too large because, once again, calibration effect on the MDRD study results are only relevant in the lower values of creatinine $(0.5-2 \mathrm{mg} /$ dl). Within this specific range, the slope appears closer to 1 , and not to 0.906 if higher values are included [21]. Accordingly, in a study concerning the creatinine calibration of the NHANES creatinine values, Selvin et al. [22] showed a slope of 1 between creatinine values measured with the Roche enzymatic method and the Beckman Jaf- 

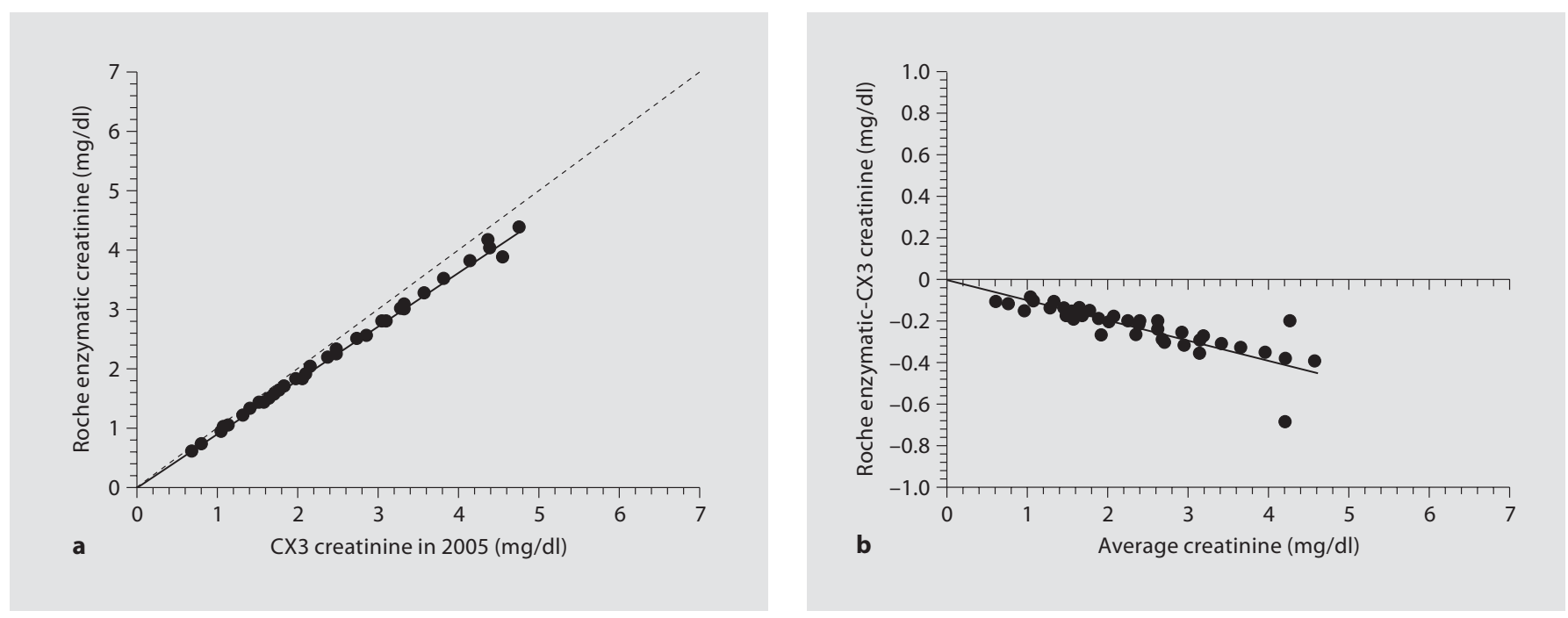

Fig. 2. Roche enzymatic versus Beckman assays using calibration panel. a Intercept set to zero was not significant; slope $0.906, \mathrm{r}^{2}=0.9994$. b Bland-Altman plot [reproduced with permission from 18].

fé method used in NHANES 2001-2002 and 2003-2004 studies. In Selvin's study, mean creatinine values used for calibration are in the important 'low' range (0.982 and $0.977 \mathrm{mg} / \mathrm{dl}$ ). When one restricts the results of calibration between the Beckman Jaffé and Roche enzymatic creatinine determinations to the range of creatinine lower than $2 \mathrm{mg} / \mathrm{dl}$, the regression coefficient between the two methods is close to 1 . The factor 175 may be too low. The true factor should be closer than 186 . The new choice of the factor 175 may contribute to the underestimation of eGFR by the thus modified MDRD study equation and to the overestimation of CKD $[21,23]$.

\section{Concepts of Critical Difference}

Even if we have criticized the way the new IDMStraceable equation has been elaborated, we totally agree with the need for standardization of the methods of creatinine measurement. However, even when this harmonization will be obtained, all limitations of the creatinine-based equations will not disappear. One should know the concept of critical difference, which is fundamental for biological variables used for ongoing care of patients, as is the serum creatinine [24]. The critical difference can be defined as the smallest change in results which is not due to chance. It is dependent of the analytical coefficient of variation $\mathrm{CV}_{\mathrm{a}}$ and the intra-individual (or biological CV) coefficient of variation $\left(\mathrm{CV}_{\mathrm{i}}\right)$. In laboratories using Jaffé methods for creatinine measurement, $\mathrm{CV}_{\mathrm{a}}$ for low creatinine values is $5.5 \%$. The intra-in- dividual coefficient of variation $\left(\mathrm{CV}_{\mathrm{i}}\right)$ for creatinine is $4.3 \%$. The critical difference for serum creatinine $(=1.414$ $\left.\times 1.96 \times\left(\mathrm{CV}_{\mathrm{a}}^{2}+\mathrm{CV}_{\mathrm{i}}^{2}\right)^{0.5}\right)$ is thus $19 \%$. A creatinine value of $1 \mathrm{mg} / \mathrm{dl}$ is thus, from an analytical point of view, not different from 1.19 or $0.81 \mathrm{mg} / \mathrm{dl}$. When the two latter values are used in the MDRD equation (for a white man of 60 years), the results are 66 and $103 \mathrm{ml} / \mathrm{min} / 1.73 \mathrm{~m}^{2}$, respectively, while the eGFR for a serum creatinine of $1 \mathrm{mg} / \mathrm{dl}$ would be $81 \mathrm{ml} / \mathrm{min} / 1.73 \mathrm{~m}^{2}$. The absolute differences between the lower and upper limit eGFRs and the eGFR value for a serum creatinine of $1 \mathrm{mg} / \mathrm{dl}$ are 15 and $22 \mathrm{ml} / \mathrm{min} / 1.73 \mathrm{~m}^{2}$, respectively. Because the $\mathrm{CV}_{\mathrm{a}}$ rises with decreasing creatinine values, the critical difference of creatinine is still higher for serum creatinine values below $1 \mathrm{mg} / \mathrm{dl}$. Potential differences in creatininebased formulae which are merely due to the analytical 'error' of measurement are thus not trivial.

The critical difference can be decreased with better $\mathrm{CV}_{\mathrm{a}}$, but a lot of improvement seems difficult to obtain with the actual creatinine measurement. If a $\mathrm{CV}_{\mathrm{a}}$ of $2 \%$ can be reached, notably with the enzymatic methods, the biological variation of creatinine is unchanged. With enzymatic methods, then, the critical difference could decrease to $13 \%$, but variability of eGFR will remain. Using the numbers of the preceding example, these will be 14 and $11 \mathrm{ml} / \mathrm{min} / 1.73 \mathrm{~m}^{2}$, respectively. To repeat, in normal creatinine ranges, small changes in creatinine concentrations have considerable consequences in GFR estimation and precision [25]. 
Table 3. Classification of CKD according the KDOQI guidelines

\begin{tabular}{ll}
\hline $\begin{array}{l}\text { Estimated GFR } \\
\mathrm{ml} / \mathrm{min} / 1.73 \mathrm{~m}^{2}\end{array}$ & Clinical significance \\
\hline$\geq 90$ & $\begin{array}{l}\text { With another abnormality }{ }^{1}, \\
\text { otherwise regard as normal }\end{array}$ \\
\hline $60-89$ & $\begin{array}{l}\text { With another abnormality }{ }^{1}, \\
\text { otherwise regard as normal }\end{array}$ \\
\hline $30-59$ & Moderate impairment \\
\hline $15-29$ & Severe impairment \\
\hline$<15$ & \begin{tabular}{l} 
Advanced renal failure \\
\hline 1
\end{tabular} \\
\hline $\begin{array}{l}\text { regarded as normal unless they have evidence of kidney disease } \\
\text { (persistent proteinuria or hematuria, or both, microalbuminuria } \\
\text { in patients with diabetes, structural kidney disease such as poly- } \\
\text { cystic kidney disease in adults or reflux nephropathy). }\end{array}$ \\
\hline
\end{tabular}

\section{Other Limitations of the MDRD Study Equation}

\section{Impact on the CKD Classification}

The classification of CKD was proposed in 2002 by the K/DOQI (Kidney Diseases Outcomes and Quality Initiative) and KDIGO (Kidney Disease Improving Global Outcomes) (table 3) [1]. The levels of GFR separating the different stages are much discussed [26]. That a subject with an eGFR $<60 \mathrm{ml} / \mathrm{min} / 1.73 \mathrm{~m}^{2}$ always has true disease is questionable. This is especially true for older people because there is a natural decline in GFR with advancing age. The question of the 'normal range' of the GFR is still not fully resolved, as has been very elegantly shown by Glassock [26] in a recent editorial. We have illustrated the analytical limitations of creatinine that cause an imprecision of the MDRD study equation in the high values of GFR. These limitations are relevant to GFR estimation in the $60 \mathrm{ml} /$ $\mathrm{min} / 1.73 \mathrm{~m}^{2}$ range and all the more for higher ranges of eGFR. As we have shown, and even if traceability of creatinine and enzymatic methods are clear improvements, the precision in this range of GFR remains insufficient. This is acknowledged by Levey and colleagues [17] who recommend laboratories not to report the absolute values of the MDRD equation for results $>60 \mathrm{ml} / \mathrm{min} / 1.73 \mathrm{~m}^{2}$, but simply to state that they are $>60 \mathrm{ml} / \mathrm{min} / 1.73 \mathrm{~m}^{2}$. We extend this opinion to further state that to differentiate stage $1 \mathrm{CKD}$ from stage 2 is unhelpful in clinical daily practice and should be abandoned. This has been also suggested by other authors $[25,27,28]$ and is also stated in the Australian guidelines (CARI guidelines) [29].

\section{Impact on the Epidemiology}

Because the MDRD equation overestimates GFR, this equation will overestimate CKD prevalence in epidemiological studies [2]. For example, that $10 \%$ of the general population has true CKD is questionable $[23,26]$. It remains possible that in the absence of progressive kidney disease, levels of GFR in the 60 - to $90-\mathrm{ml} / \mathrm{min}$ range may carry cardiovascular risk, but this, too, is debatable, as is the entirely speculative effect of improving such levels of kidney function on that associated risk.

\section{MDRD Study Equation in CKD Patients: An Estimate That Is Not Magic}

In several studies, the MDRD study equation has been shown to be a good way to estimate the GFR in subjects with CKD [9]. However, in other subjects with kidney disease, the accuracy and the precision of the equation are less impressive. Thus, for hospitalized patients, especially those in intensive care and in transplantation, all formula-based estimates of eGFR are prone to substantial error $[27,30,31]$. This is not only because of reduced activity and muscle mass, but also because of day-to-day changes in kidney function. In all these patients, the MDRD study equation may be misleading.

\section{MDRD Study Equation in Practice}

In this review, we have underlined some limitations linked to formula-based estimates of the GFR. We agree that the MDRD study equation provides a good estimate of GFR, specifically in subjects with CKD who are in the steady state. We use and recommend that MDRD study equation results should be stated by clinical laboratories based on the serum creatinine, age, gender, and race, but without giving the absolute result when GFR is $>60 \mathrm{ml} /$ $\min / 1.73 \mathrm{~m}^{2}$. For particular populations, such as subjects on chronic dialysis and subjects with acutely changing kidney function, the formula-based estimates of GFR are false, and should be omitted or ignored. In any case, current formula-based estimates of the GFR remain estimations and we must keep this in mind when analyzing their results. The use of cystatin $\mathrm{C}$ as a new plasma marker of cystatin $\mathrm{C}$ and of cystatin C-based equations for better estimating GFR is increasing but it must be still validated before its implementation in daily clinical practice [32]. 


\section{References}

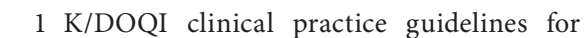
chronic kidney disease: evaluation, classification, and stratification. Am J Kidney Dis 2002;39:S1-S266.

-2 Coresh J, Selvin E, Stevens LA, Manzi J, Kusek JW, Eggers P, Van Lente F, Levey AS: Prevalence of chronic kidney disease in the United States. JAMA 2007;298:2038-2047.

-3 Perrone RD, Madias NE, Levey AS: Serum creatinine as an index of renal function: new insights into old concepts. Clin Chem 1992; 38:1933-1953.

4 Cockcroft DW, Gault MH: Prediction of creatinine clearance from serum creatinine. Nephron 1976;16:31-41.

5 Levey AS, Bosch JP, Lewis JB, Greene T, Rogers N, Roth D: A more accurate method to estimate glomerular filtration rate from serum creatinine: a new prediction equation. Modification of Diet in Renal Disease Study Group. Ann Intern Med 1999;130:461-470.

-6 Lewis J, Agodoa L, Cheek D, Greene T, Middleton J, O'Connor D, Ojo A, Phillips R, Sika $\mathrm{M}$, Wright J Jr: Comparison of cross-sectional renal function measurements in AfricanAmericans with hypertensive nephrosclerosis and of primary formulas to estimate glomerular filtration rate. Am J Kidney Dis 2001;38:744-753.

-7 Zuo L, Ma YC, Zhou YH, Wang M, Xu GB, Wang HY: Application of GFR-estimating equations in Chinese patients with chronic kidney disease. Am J Kidney Dis 2005;45: 463-472.

-8 Imai E, Horio M, Nitta K, Yamagata K, Iseki K, Tsukamoto Y, Ito S, Makino H, Hishida A, Matsuo S: Modification of the Modification of Diet in Renal Disease (MDRD) study equation for Japan. Am J Kidney Dis 2007; 50:927-937.

-9 Stevens LA, Coresh J, Greene T, Levey AS: Assessing kidney function - measured and estimated glomerular filtration rate. $\mathrm{N}$ Engl J Med 2006;354:2473-2483.

- 10 Froissart M, Rossert J, Jacquot C, Paillard M, Houillier P: Predictive performance of the modification of diet in renal disease and Cockcroft-Gault equations for estimating renal function. J Am Soc Nephrol 2005;16: 763-773.

-11 Rigalleau V, Lasseur C, Perlemoine C, Barthe N, Raffaitin C, Chauveau P, Combe C, Gin $\mathrm{H}$ : Cockcroft-Gault formula is biased by body weight in diabetic patients with renal impairment. Metabolism 2006;55:108-112.
12 Verhave JC, Fesler P, Ribstein J, du Cailar G, Mimran A: Estimation of renal function in subjects with normal serum creatinine levels: influence of age and body mass index. Am J Kidney Dis 2005;46:233-241.

13 Delanaye P, Radermecker RP, Rorive M, Depas G, Krzesinski JM: Indexing glomerular filtration rate for body surface area in obese patients is misleading: concept and example. Nephrol Dial Transplant 2005;20:20242028.

14 Delanaye P, Cavalier E, Krzesinski JM, Chapelle JP: Why the MDRD equation should not be used in patients with normal renal function (and normal creatinine values)? Clin Nephrol 2006;66:147-148.

5 Coresh J, Eknoyan G, Levey AS: Estimating the prevalence of low glomerular filtration rate requires attention to the creatinine assay calibration. J Am Soc Nephrol 2002;13:28112812.

16 Van Biesen W, Vanholder R, Veys N, Verbeke F, Delanghe J, de Bacquer D, Lameire N: The importance of standardization of creatinine in the implementation of guidelines and recommendations for CKD: implications for CKD management programmes. Nephrol Dial Transplant 2005;21:77-83.

17 Myers GL, Miller WG, Coresh J, Fleming J, Greenberg N, Greene T, Hostetter T, Levey AS, Panteghini M, Welch M, Eckfeldt JH: Recommendations for improving serum creatinine measurement: a report from the laboratory working group of the national kidney disease education program. Clin Chem 2006;52:5-18.

18 Levey AS, Coresh J, Greene T, Marsh J, Stevens LA, Kusek JW, Van Lente F: Expressing the modification of diet in renal disease study equation for estimating glomerular filtration rate with standardized serum creatinine values. Clin Chem 2007;53:766-772.

19 Levey AS, Coresh J, Greene T, Stevens LA, Zhang YL, Hendriksen S, Kusek JW, Van Lente F: Using standardized serum creatinine values in the modification of diet in renal disease study equation for estimating glomerular filtration rate. Ann Intern Med 2006;145:247-254.

20 Vickery S, Stevens PE, Dalton RN, van Lente F, Lamb EJ: Does the ID-MS traceable MDRD equation work and is it suitable for use with compensated Jaffé and enzymatic creatinine assays? Nephrol Dial Transplant 2006;21: 2439-2445.
21 Delanaye P, Cavalier E, Maillard N, Krzesinski JM, Mariat C: Creatinine calibration in NHANES: is a revised MDRD study formula needed? Am J Kidney Dis 2008;51:709-710.

-22 Selvin E, Manzi J, Stevens LA, Van Lente F, Lacher DA, Levey AS, Coresh J: Calibration of serum creatinine in the National Health and Nutrition Examination Surveys (NHANES) 1988-1994, 1999-2004. Am J Kidney Dis 2007;50:918-926.

23 Delanaye P, Cavalier E, Krzesinski JM: Determining prevalence of chronic kidney disease using estimated glomerular filtration rate. JAMA 2008;299:631.

$\checkmark 24$ Fraser CG, Harris EK: Generation and application of data on biological variation in clinical chemistry. Crit Rev Clin Lab Sci 1989;27:409-437.

25 MacGregor MS, Boag DE, Innes A: Chronic kidney disease: evolving strategies for detection and management of impaired renal function. QJM 2006;99:365-375.

26 Glassock RJ, Winearls C: An epidemic of chronic kidney disease: fact or fiction? Nephrol Dial Transplant 2008;23:1117-1121.

$>27$ Giles PD, Fitzmaurice DA: Formula estimation of glomerular filtration rate: have we gone wrong? BMJ 2007;334:1198-1200.

28 Bauer C, Melamed ML, Hostetter TH: Staging of chronic kidney disease: time for a course correction. J Am Soc Nephrol 2008; 19:844-846.

29 Johnson D: The CARI guidelines: Evaluation of renal function. Nephrology (Carlton) 2005;10(suppl 4):S133-S176.

30 Hoste EA, Damen J, Vanholder RC, Lameire NH, Delanghe JR, Van den Hauwe K, Colardyn FA: Assessment of renal function in recently admitted critically ill patients with normal serum creatinine. Nephrol Dial Transplant 2005;20:747-753.

31 Mariat C, Maillard N, Phayphet M, Thibaudin L, Laporte S, Alamartine E, Berthoux F: Estimated glomerular filtration rate as an end point in kidney transplant trial: where do we stand? Nephrol Dial Transplant 2008; 23:33-38.

32 Stevens LA, Coresh J, Schmid CH, Feldman HI, Froissart M, Kusek J, Rossert J, Van Lente F, Bruce RD, Zhang YL, Greene T, Levey AS: Estimating GFR using serum cystatin C alone and in combination with serum creatinine: a pooled analysis of 3,418 individuals with CKD. Am J Kidney Dis 2008;51: 395-406. 


\section{Editorial Comment}

M. El Nahas, Sheffield

In this paper, Delanaye and Cohen critically review the validity of formulae used to estimate GFR. Their emphasis is on the limitations of the most commonly used MDRD and Cockcroft-Gault formulae. Their criticism, severe at times, reiterates concerns expressed by many nephrologists on the accuracy of these formulae for screening and detection of CKD within the general population. Clearly, such formulae have serious limitations at both spectra of CKD; CKD-1 and -2 as well as CKD-5. The authors also review adaptations to the MDRD formula for various non-Caucasian populations. These may facilitate the applicability of this formula in a number of countries and ethnicities. Finally, it has to be acknowledged that in spite of their limitations, the wide use of these formulae, especially amongst non-nephrologists, has focused minds on the degree of severity of CKD in a number of patients where it may have been overlooked in the past. Also, these formulae may open up the way in the future for new calculations, some based on serum cystatin $\mathrm{C}$ levels and others on a combination of serum creatinine and cystatin $\mathrm{C}$, that may prove more accurate and adaptable. 